\title{
Desafíos de la comunicación pública de epidemias a las políticas de salud en la Argentina
}

\section{Challenges of epidemics public communication to health policies in Argentina}

Recibido: 11/10/2019

Aceptado: 03/02/2020

Publicado: 26/06/2020
Mónica Petracci mpetracci@sociales.uba.ar https://orcid.org/0000-0003-4504-8457 Universidad de Buenos Aires (Argentina)

Paula Rodríguez Zoya paula.rodriguezzoya@conicet.gov.ar https://orcid.org/0000-0003-3623-3992

Universidad de Buenos Aires

Consejo Nacional de Investigaciones Científicas y Técnicas, CONICET (Argentina)

Resumen: El objetivo del artículo es reflexionar sobre la comunicación de políticas públicas de salud en el caso de las epidemias en la Argentina desde el campo de la comunicación y la salud. El diseño metodológico se basó en la sistematización y clasificación de hallazgos de investigaciones sociales sobre las epidemias de $\mathrm{VIH} /$ sida, cólera, gripe H1N1 y dengue. El propósito es desarrollar los lineamientos de un marco de investigación y comunicación destinado a fortalecer las capacidades para afrontar el desafío de la comunicación pública de epidemias en la sociedad contemporánea.

Palabras clave: Comunicación y salud, Epidemias, Políticas públicas, Riesgo, Nuevas tecnologías de información y comunicación. 
Abstract: The main objective of the article is to reflect on the communication of public health policies about epidemics in Argentina from the Health Communication perspective. The methodological design was based on the systematization and classification of social research findings about AIDS, Cholera, H1N1 fever and Dengue. The purpose is to develop the outlines of a research and communication framework designed to strengthen the skills to cope with the challenge of public communication on epidemics in the contemporary society.

Key words: Health communication, Epidemics, Public policies, Risk, New information and communication technologies.

\section{Introducción}

Las epidemias influyen sobre las ideas (sociales, políticas, religiosas, médicas, entre otras) ya sea para reforzarlas o modificarlas (Ranger \& Slack, 1992; Rosenberg, 1992) y visibilizan tanto el estado en que se encuentran cuanto las respuestas de las sociedades. Representaciones precisas que invitan a reflexionar sobre las características generadas históricamente durante el desenvolvimiento de las epidemias se encuentran en las producciones académicas y literarias, tales como El diario del año de la peste, de Daniel Defoe (1722) y La peste, de Albert Camus (1947), entre otras.

Si bien con diferencias basadas en la naturaleza de cada brote epidémico, han circulado teorías contrapuestas sobre su origen, ideas sobre el "castigo divino", el temor al extranjero, interpretaciones morales sobre enfermedades vinculadas a la sexualidad; reacciones de discriminación y reacciones de solidaridad; estigmatización de personas afectadas, medidas de exclusión como cuarentena y cordón sanitario; y normativas de prevención fijadas por los gobiernos como la vacunación obligatoria. Las epidemias cuentan con una larga trayectoria en la historia de la humanidad y actualmente, lejos de convertirse en un fenómeno arcaico o marginal, constituyen un problema socialmente relevante que involucra múltiples actores sociales y desafíos, sobre todo al momento de pensar y abordar la comunicación pública de las mismas.

El objetivo del artículo es reflexionar sobre la comunicación de políticas públicas de salud en el caso de las epidemias en la Argentina. El diseño meto- 
dológico del estudio es propositivo. Consistió en la sistematización y clasificación de investigaciones sociales sobre diferentes casos de epidemias (VIH/ sida, cólera, gripe H1N1 y dengue) desatadas en ese país entre la década de 1990 y las primeras de este nuevo siglo.

El propósito es desarrollar los lineamientos de un marco de investigación (entendida como una de las bases de la planificación, formulación e implementación de las políticas) y comunicación (entendida como dimensión transversal del proceso de las políticas públicas y como derecho a la información), cuyos destinatarios principales son los tomadores de decisión gubernamentales, dadas las responsabilidades políticas y técnicas de sus decisiones y la alta valoración que dichos actores sociales asignan a la dimensión comunicacional, especialmente a partir de la década de los años 2000 (Petracci, 2015a; Petracci \& Rodríguez Zoya, 2018b, 2019). También son destinatarios los representantes de organizaciones no gubernamentales y los comunicadores sociales en tanto actores sociales partícipes de la formulación, implementación y comunicación de políticas públicas.

El enfoque elegido es la de "Comunicación y Salud". Los puntos de partida teóricos de dicho enfoque son los siguientes. En primer lugar, se trata de un "campo", entendido desde la noción bourdesiana (Araujo \& Cardoso, 2007; Cardoso \& Araujo, 2009; Cuberli \& Soares, 2015). El segundo punto de partida es el carácter "complejo" del campo, entendido desde la matriz epistémica de la complejidad (Rodríguez Zoya, 2017). En tercer lugar, la "heterogeneidad" entendida desde el esbozo de una cartografía en la que aparecen entrelazados diferentes ámbitos, actores sociales y temas de salud (Petracci \& Waisbord, 2011; Petracci, 2012, 2015a, 2015b; Rodríguez Zoya, 2017).

La decisión de reflexionar sobre las epidemias para desarrollar un marco de investigación y comunicación responde a varios factores referidos al enfoque y al tema. Los factores referidos al enfoque son los siguientes:

- El puntapié inicial dado por la participación en el curso "Epidemias, Jornalismo e Políticas Públicas de Saúde" coordinado por las Doctoras Katia Lerner y Janine Cardoso en el Instituto de Comunicación e Información Científica y Tecnológica en Salud y la Fundación Oswaldo Cruz FIOCRUZ (Rio de Janeiro, Brasil), en septiembre de 2018. La participación en dicho curso derivó en la redacción de un artículo 
(Petracci \& Rodríguez Zoya, 2018c) que abordó, a través de sendas instancias analíticas, el entramado de relaciones entre las epidemias, las políticas públicas y los actores involucrados en la comunicación (funcionarios y periodistas).

- El interés y la dedicación de las autoras a pensar en el campo de "Comunicación y Salud" para contribuir a su consolidación y rigurosidad académicas, plasmadas en la coordinación de investigaciones, publicaciones y, en menor medida, en producciones comunicacionales.

- La convicción de que "Comunicación y Salud" es un campo de conocimiento y práctica en el que se interrelacionan conceptos y herramientas cuya síntesis excede el debate binario entre teoría y técnica o bien entre modelos lineales y procesuales. Por el contrario, el campo requiere claridad teórica, complementariedad de enfoques y pericia comunicacional.

Los factores referidos al tema son los siguientes:

- El crecimiento sostenido de las noticias sobre salud en los medios de comunicación (Polino et al., 2006; Petracci \& Waisbord 2011; Tabakman, 2011; Waisbord, 2011; Loewy \& Petracci, 2015).

- Las características recurrentes y específicas de la comunicación de cada epidemia.

- La relevancia asignada por la Organización Mundial de la Salud (OMS) a las epidemias.

- El interés por las epidemias como problema de investigación y como materia de comunicación dadas las dificultades, no fácilmente reconciliables, de los requerimientos de noticiabilidad periodística en escenarios locales y globales de riesgo e incertidumbre.

Las hipótesis de trabajo que guían el análisis, emergentes del enfoque y tipo de estudio, son las siguientes:

- H1: La comunicación de las epidemias mantiene relaciones directas con los escenarios políticos.

- H2: La comunicación de las epidemias difiere según se trate de casos ligados a ciclos noticiosos que coinciden con el ciclo del brote (cólera, dengue, chikungunya, zika) o de casos cuya aparición en los medios está ligada a hallazgos científicos y crisis simbólicas (VIH/sida). 


\section{Comunicación y salud}

\subsection{Como "campo"}

La literatura enfatiza este punto de partida desde fines del siglo pasado en tanto búsqueda por renovar pensamientos y prácticas. Araujo \& Cardoso (2007) definieron "Comunicación y Salud" desde la concepción bourdesiana de campo, como un espacio sociodiscursivo integrado tanto por teorías, modelos, metodologías, instituciones, políticas públicas, prácticas y discursos, como por agentes de salud en diferentes tipos de relaciones (luchas, conflictos, negociaciones). Para las autoras, la elección de una denominación que incluye el conectivo " $y$ " (en lugar de las denominaciones "comunicación para la salud" y "comunicación en salud") se aleja de las visiones que entienden lo comunicacional como una herramienta al servicio de la salud. En un artículo posterior, las autoras sostienen que "Comunicación y Salud" expresa una articulación y delimita "un territorio de disputas específicas, aunque atravesado y formado por los elementos característicos de uno, de otro y de la formación social más amplia que los alberga" (Cardoso \& Araujo, 2009, p. 95). En la misma dirección, Cuberli \& Soares (2015, p. 22) sostienen lo siguiente:

Nuestro modo de mirar percibe la comunicación como un proceso social de producción de los sentidos que ocurre a través de los discursos sociales, que compiten en las múltiples arenas públicas por el poder de crear la realidad. Entre otros, las arenas de investigación, formación/ enseñanza, intervención, legislación, medios de comunicación, producción y comunicación científica.

\subsection{Como "campo complejo"}

Rodríguez Zoya (2017) renueva la lectura en la búsqueda por comprender el carácter complejo del campo de "Comunicación y Salud" desde la teoría de la complejidad desarrollada por Morin (2001), una matriz epistémica que habilita a pensar interrogantes a través de matrices no dicotómicas y de lógicas multidimensionales e interdisciplinarias. En ese sentido, se plantean interpelaciones del pensamiento complejo al campo de "Comunicación y Salud" en tres direcciones: 
En primer lugar, se vislumbra la tarea de problematizar el dominio de fenómenos comprendidos en este campo como sistemas complejos. Esto implica movilizar los conceptos, métodos y técnicas del pensamiento y ciencias de la complejidad como estrategias de indagación para la construcción de sus objetos de estudio. Es decir, desarrollar críticamente la complejidad como estrategia de objetivación relevante para la investigación e intervención en Comunicación y Salud.

En segundo lugar, la objetivación de sistemas complejos de comunicación-salud suscita una implicancia práctico-epistémica por cuanto requiere concebir estrategias de investigación interdisciplinarias para la comprensión sistémica de dichas problemáticas. Ahora bien, si las disciplinas constituyen campos de saber-poder, entonces, la práctica interdisciplinaria de la ciencia no se agota ni se reduce en el diálogo de saberes ni en la articulación de conocimientos desarticulados. Bien por el contrario, el desarrollo práctico de estrategias de investigación interdisciplinarias en sistemas complejos implica poner en cuestión las relaciones de poder que estructuran el campo de Comunicación y Salud.

En tercer lugar, la idea de complejidad como un nuevo modo de objetivación es necesaria pero insuficiente en sí misma. Además, se requiere concebir un modo de reflexividad tendiente a problematizar las propias prácticas epistémicas y nuestro modo de pensamiento. (Rodríguez Zoya, 2017, pp. 58-59)

En otros términos,

se trata de hacer explícitas y de reflexionar sobre las matrices de pensamiento con las que interrogamos y organizamos las problemáticas del mundo de la experiencia. Si la objetivación implica un pensamiento de primer orden centrado en el objeto de conocimiento, la reflexividad conlleva un pensamiento de segundo orden orientado a problematizar el conocimiento del conocimiento. En suma, la complejidad como desafío enhebra dos planos: la complejidad como modo de objetivación y como modo de reflexividad para abordar las cuestiones de Comunicación y Salud. (Rodríguez Zoya, 2017, p. 59) 
El carácter complejo de este campo también es fundamentado en virtud de una particular forma de concebir y comprender los problemas de la "Comunicación y Salud" como cuestiones que entrañan una indisoluble imbricación de procesos comunicacionales y temas o problemáticas vinculadas a la salud. Esta característica es entendida a partir del principio de "unidualidad" (categoría central del enfoque del pensamiento complejo), que refiere a una "unidad-múltiple" que busca dar cuenta del carácter multidimensional de los aspectos humanos y fenómenos de la realidad, y de la articulación de planos heterogéneos que se vuelven irreductibles entre sí.

En oposición a una lógica simplificadora o reduccionista que piensa en la unidad sin diversidad y en la diversidad sin unidad, Morin (2001) sostiene el principio de unidualidad y afirma que "el corazón de la complejidad es la imposibilidad tanto de homogeneizar como de reducir: es la cuestión del unitas multiplex" ( $\mathrm{p}$. 149). Rodríguez Zoya (2019) hace una lectura de la "Comunicación y Salud" siguiendo estos conceptos del paradigma de la complejidad y propone

el principio de unidualidad comunicación-salud como clave de inteligibilidad de los temas, fenómenos y problemas que son abordados en el campo de Comunicación y Salud. Esto es, que el conjunto de problemáticas concernientes a este campo se caracteriza por pertenecer, de modo simultáneo, totalmente a la comunicación y totalmente a la salud. (p. 95)

En este sentido, los diversos temas que conciernen a la "Comunicación y Salud" condensan un entramado de miradas, abordajes, prácticas de investigación e intervención; debates, tomas de decisión y estrategias que convocan y remiten simultáneamente a la comunicación y a la salud, por lo cual conllevan la unidualidad comunicación-salud como rasgo característico de este campo complejo.

\subsection{Como "campo heterogéneo"}

La heterogeneidad visibiliza la porosidad de la composición y los límites del campo y, al mismo tiempo, es una pieza clave de la riqueza analítica (Petracci \& Waisbord, 2011; Petracci, 2012; Cófreces et al., 2014; Del Pozo et al., 2015; Petracci, 2015a, 2015b). Una cartografía de esa heterogeneidad despliega diferentes ámbitos comunicacionales, actores y temas. 
Los ámbitos (cara a cara, institucionales, públicos gubernamentales y no gubernamentales, mediáticos e Internet) se interrelacionan en numerosos ejemplos: la relación médico-paciente, las consultas de salud online, eHealth, los vínculos en un equipo de salud, el circuito de la toma de decisiones desde las máximas autoridades de un ministerio de salud hasta los jefes de servicio de un hospital público, la calidad de la atención recibida por los usuarios y las usuarias, la agenda pública y mediática, las campañas dirigidas a la ciudadanía en general o a sectores específicos de ella, el periodismo científico y en salud, las intervenciones comunitarias y el trabajo con organizaciones sociales, las acciones de la industria farmacéutica, entre otros tantos casos. (Petracci \& Waisbord, 2011; Petracci et al., 2017; Petracci \& Rodríguez Zoya, 2018b).

Una multiplicidad de actores sociales (la ciudadanía, pacientes y profesionales de la salud, funcionarios públicos de diferentes jerarquías, comunicadores sociales, entre otros) motoriza los ámbitos mencionados previamente. Actualmente, en el marco de cambios (sociales en general y tecnológicos en particular) dentro de las sociedades globalizadas y profundamente desiguales, el énfasis del campo de "Comunicación y Salud" recae en la construcción de autonomía y la ampliación de ciudadanía en lo que respecta a la salud individual y colectiva.

La variedad temática refiere a las innumerables situaciones ligadas a la salud y la enfermedad que motivan reflexiones y acciones comunicacionales (dengue, diabetes, cáncer, cólera, tabaquismo, tuberculosis, VIH/sida, vacunas, epidemias) como también los nuevos temas que, hoy por hoy, incluye la agenda de la salud desde una perspectiva de derechos (alimentación, salud sexual y reproductiva, medio ambiente y cambio climático, violencias, entre otros). En la cartografía de la heterogeneidad del campo, este artículo apunta a las epidemias como "tema"; a las políticas públicas, los medios y las redes sociales como "ámbitos"; y a los funcionarios públicos (tomadores de decisión), periodistas, publicistas y comunicadores de las agencias gubernamentales como "actores".

\section{Metodología}

El estudio es de tipo propositivo. Se inició a partir de un trabajo de lectura sistemática de cinco investigaciones primarias sobre las epidemias de VIH/ sida, cólera, gripe H1N1 y dengue, cuyas fuentes son secundarias y cuyos 
procesos de relevamiento de la información, análisis y posterior publicación eran conocidos por alguna de las autoras de este artículo y formaban parte de su acervo personal. En otros términos, no se trata de una revisión sistemática que sintetiza los hallazgos cualitativos y cuantitativos de la literatura disponible, sino de una lectura sistemática de documentos seleccionados por su cercanía con el trabajo de las autoras.

\section{Resultados}

Actualmente, en el marco de una sociedad globalizada, las epidemias son una preocupación central de los gobiernos, los organismos internacionales y la sociedad civil. Tedros Adhanom Ghebreyesus, actual Director General de la Organización Mundial de la Salud, ofrece líneas abajo una perspectiva global de la problemática endémica que nos aqueja a nivel global:

En un campamento militar, un cocinero acude al servicio médico con fiebre, dolor de garganta y malestar general. A los pocos minutos, aparece un segundo soldado con síntomas similares. A la hora del almuerzo hay más de 100 casos, y más de 500 al final de la semana. Los batallones del campamento están luchando en tierra extranjera. La vida cerrada del cuartel y los grandes movimientos de tropas crean las condiciones ideales para la propagación del virus. En cuestión de meses, la epidemia asola cinco continentes. Los síntomas son fiebre, dolor de cabeza y dolores musculares y articulares. A medida que la situación empeora, los pacientes adquieren un color azulado y se asfixian porque tienen los pulmones llenos de líquido. No hay vacunas para detener el virus, ni fármacos para combatirlo. Muchas de las víctimas son jóvenes en sus años más productivos. Se cierran escuelas, lugares de culto, teatros y otros lugares públicos. Se escalona la hora de cierre de los negocios para evitar la congestión del transporte público. Los funerales no duran más de 15 minutos para reducir al mínimo los contactos. Hay escasez de ataúdes. Y de pronto la pandemia termina tan súbitamente como empezó. Se ha infectado un tercio de la población mundial y han muerto 100 millones de personas ... No os hablo de una pesadilla del futuro. Esto fue exactamente lo que ocurrió durante la epidemia de gripe "española" en 1918 ... la epidemia más mortal de la historia. Mató a más gente que la Primera Guerra Mundial en sí 
misma. Pero sus enseñanzas son tan pertinentes hoy como entonces: una epidemia devastadora puede comenzar en cualquier momento en cualquier país y matar a millones de personas porque no estamos preparados. Porque seguimos siendo vulnerables.

El desastre está a la vuelta de la esquina cuando los sistemas de vigilancia no son adecuados, los profesionales sanitarios no acuden al trabajo porque no se les paga desde hace meses, hay escasez de medicamentos o no hay sistemas de prevención y control de las infecciones. Pero no basta con responder a los brotes. Hay que hacer todo lo posible por prevenirlos. Para ello tenemos que abordar la causa primaria de la inseguridad sanitaria: la falta de acceso de las personas más vulnerables a servicios de salud esenciales. En última instancia, la mayor amenaza para la seguridad sanitaria es la inexistencia de una cobertura sanitaria universal ... Los signos más precoces de un brote pueden pasar inadvertidos cuando la gente no dispone de un profesional sanitario cerca de su casa o no se puede pagar el uso de servicios que sí existen. Pero cuando puede acceder a servicios de calidad sin verse expuesta a dificultades económicas, es posible detener una epidemia devastadora incluso antes de que empiece. Las nuevas tecnologías, el gran volumen de datos y la cibersalud serán fundamentales para mejorar la vigilancia y ampliar el acceso a los servicios, pero, sorprendentemente, en muchos casos las mejores defensas no requieren grandes tecnologías. Las evidencias y la experiencia revelan que la cobertura sanitaria universal está al alcance de todos los países, cualquiera que sea su nivel de ingresos.

No sabemos cuándo tendrá lugar la próxima pandemia, pero sí sabemos que se cobrará un precio terrible, tanto en vidas humanas como en la economía mundial. Hasta puede que sea causa de inestabilidad política. La cuestión es: ¿podemos conseguir un mundo sin pandemias? No hay ninguna garantía, pero con una preparación meticulosa y una respuesta rápida podemos evitar que se descontrolen la mayoría de los brotes y reducir el impacto de aquellos que tengan una propagación internacional. (Adhanom, 2018)

Si bien extensa, la cita refleja la necesidad y la urgencia por reforzar la prevención de cara a los gobiernos y, por otro lado, la ampliación de la cobertura 
y el acceso al sistema de salud. Tras esta exposición, se subraya que las investigaciones analizadas muestran la heterogeneidad y la complejidad de la comunicación de las epidemias en el marco del escenario público y político contemporáneo:

- La fuerte relación de las estrategias comunicacionales (lentas o a tiempo; claras o confusas) con los modelos políticos.

- Las complicadas relaciones entre decisores y periodistas o bien entre la noticia en salud y los criterios de noticiabilidad del medio.

- Las narraciones de la prensa gráfica que sacan a la luz aquellas características recurrentes en la comunicación de las epidemias (la estigmatización de personas afectadas, la espectacularidad, el temor al exterior, etcétera).

Además, de las investigaciones analizadas, se desprenden interrogantes que devienen en desafíos para la comunicación pública de las epidemias: ¿Qué lugar ocupa la investigación en las etapas de las políticas públicas de salud?, ¿qué significa investigar y tomar decisiones basadas en los hallazgos de investigaciones?, ¿cómo comunicar el riesgo en escenarios comunicacionales complejos?

\subsection{Cólera y VIH/sida: dos modelos de comunicación pública y respon- sabilidad estatal}

Petracci et al. (1998) analizaron las epidemias de cólera y VIH/sida en la Argentina en el período 1991-1993 mediante un diseño que empleó fuentes primarias (entrevistas a portavoces institucionales) y secundarias (corpus de la prensa, campañas y estudios de opinión pública).

El supuesto de partida fue que los escenarios políticos-comunicacionales y el entorno económico en el que se desenvolvió cada epidemia generaron sus características distintivas. De acuerdo con esa hipótesis, las epidemias del SIDA y el cólera en la Argentina en el período 1991-1993 originaron diferentes estrategias comunicacionales (que los autores consideran más efectiva en el caso del cólera que en el del SIDA que presentó, en ese momento, una comunicación discontinua y confusa) en un marco caracterizado por el retiro estatal y una centralidad mediática creciente. De acuerdo a los autores, el 
cólera, acompañando la falta de instalaciones sanitarias y agua potable y los bajos niveles socioeconómicos, se radicó en el noroeste del país y visibilizó la necesidad de construir obras públicas de agua potable y cloacas; dejó al descubierto que los productores rurales de tabaco de las provincias de Jujuy y Salta no cumplían con la ley en cuanto a las condiciones mínimas de salud, vivienda y trabajo del personal contratado; demostró la carencia de hospitales y salas de asistencia en las zonas rurales; puso en marcha un entredicho internacional por las condiciones sanitarias de la frontera argentino-boliviana que hizo aparecer a la enfermedad como proveniente de Bolivia ante la opinión pública. El SIDA, cuya tematización pública inicial fue contemporánea a la del cólera, planteó un escenario diferente y políticamente neutralizado, en el cual el Estado aparece "libre de culpas". Su papel no fue puesto en tela de juicio porque, de entrada, fue el paciente el que estuvo inculpado y la principal discusión (sobre el preservativo) tuvo una carga ideológica (Petracci et al., 1998, pp. 199-218).

Otras dimensiones analizadas por los autores son la frecuencia de aparición de notas en la prensa y las campañas de prevención. Respecto de la primera, Petracci et al. (1998) concluyen que el cólera, desde 1991, tuvo una presencia cíclica que recrudece en el verano, ocupa los titulares y retrocede a las páginas interiores hasta ocupar un "expirante recuadro que desaparece, en realidad queda latente hasta que el calor, el hacinamiento y la contaminación lo hacen volver a la tapa de los diarios" (p. 7). Contrariamente, la información sobre VIH/sida se inició de manera esporádica, pero fue ganando espacios hasta hacerse sostenida.

Respecto de la segunda dimensión (campañas de prevención), los autores concluyen que, si bien ninguna de estas tuvo en cuenta aspectos comunicativos, las diferencias son marcadas

en lo que hace a la rapidez de la aparición pública y la claridad de los mensajes. La campaña de prevención del cólera en el período 1991/92 (antes y después del primer caso de cólera en febrero de 1992) fue casi inmediata ante la inminencia del brote y la guerra de cifras desatada por los medios; también, en general, fue clara y concisa con respecto al contenido (pese a que en un comienzo hubo algunas diferencias con respecto a la cantidad de gotas de lavandina necesarias para lavar los alimentos). En el caso del Sida, la primera campaña que tuvo reper- 
cusión en la prensa, en el período estudiado ... fue la emisión de dos spots televisivos, uno de los cuales remitía a un grupo de personalidades cantando una canción contra la discriminación sin nombrar el Sida, más parecido a un aviso de saludos navideños que a una campaña de bien público. (Petracci et al., 1998)

\subsection{Influenza H1N1: espectacularidad y fatalismo en la comunicación periodística}

En la Argentina, el primer caso de Influenza H1N1 se detectó el 7 de mayo de 2009 entre pasajeros que regresaban de México. Tuvo una circulación generalizada a nivel nacional encontrándose el pico de contagio entre el 20 de junio y el 3 de julio de ese año. Jait (2011) caracteriza el brote epidémico y analiza la cobertura periodística del diario Clarín, un matutino de referencia nacional. En relación con el primer aspecto, la autora califica a la epidemia como una severa contingencia sanitaria que demandó recursos económicos extrapresupuestarios para la compra de antivirales y la contratación de médicos, pero también provocó medidas de otro orden como el adelanto del receso de invierno para todos los niveles educativos, licencias preventivas a mujeres embarazadas, pacientes inmunodeprimidos y oncológicos, y la suspensión de actividades públicas (pp. 117-142).

Con relación a la cobertura, que ocupó más de una docena de tapas del matutino, Jait (2011) considera que la misma tuvo características alarmistas que potenciaron la gravedad del virus debido a la sostenida difusión del número de personas infectadas y fallecidas, y la apelación al miedo que provocó una contracción de la vida social. De acuerdo con sus palabras:

miedo a que el virus se extienda en el mundo; que mute, volviéndose más peligroso; que llegue a la Argentina; que lo haga en la temporada invernal coexistiendo con la gripe estacional; que falten camas en el sector público; que genere resistencia a los antivirales; que se expanda a la población menos privilegiada; que alcance al interior del país; que afecte a personas sin patologías preexistentes y que produzca más fallecimientos dentro de las fronteras nacionales, que pueda retornar en el invierno siguiente. (p. 139) 
Jait (2011) enfoca el rol del periodismo en la cobertura de las epidemias. El análisis del tratamiento discursivo del diario Clarín la lleva a concluir que

el medio no sólo enfatizó en forma desmesurada las peores expectativas del riesgo, sino que también atravesó en muchas ocasiones, la frontera del pánico. Sin duda, varios hechos "alimentaron" la espectacularidad que imprimió Clarín a la cobertura. La oscilación entre la incertidumbre y el fatalismo de las declaraciones de algunos voceros de la OMS y expertos, la escala global que asumió el H1N1, el acelerado tiempo de su expansión ... Pero también es insoslayable en el análisis otra cuestión, la del vínculo entre quienes desarrollan tareas en los medios y quienes se ocupan de la gestión de las políticas públicas, dado que dicho vínculo está condicionado no sólo por disputas políticas, sino también por las particulares lógicas de ambos sectores. (pp. 139-140)

\subsection{Dengue: entre la metáfora militar y las tecnologías de gobierno}

Eynard y Drovetta (2011) analizan cómo la epidemia de dengue, de abril de 2009, en la ciudad de Córdoba (capital de la provincia del mismo nombre ubicada en la zona central de la Argentina), fue construida por la prensa escrita de esa localidad a través de representaciones y metáforas. Del análisis de 202 artículos periodísticos, surge que el dengue fue tematizado como "enemigo a vencer" a través de una metáfora militar; como un "error o sorpresa" dado que, hasta ese momento, no se consideraba que la epidemia podría ocurrir en esa provincia; y, finalmente, como un "redistribuidor de riesgos" porque no sólo los charcos y fuentes de agua fueron factores de posible contagio sino también las piscinas ubicadas en las casas de las personas con mayor poder adquisitivo.

Rodríguez Zoya (2018) analiza la problemática del dengue y de otras enfermedades como zika, chikungunya y fiebre amarilla, todas estas transmitidas por el mosquito Aedes aegypti. Situado en la intersección entre políticas públicas, epidemias y periodismo, el dengue es tomado "como caso a través del cual reflexionar sobre los modos en que los discursos sociales configuran sentidos sobre los problemas de salud pública y sobre las estrategias de las políticas formuladas ante tales cuestiones" (p. 16). En este sentido, la autora expresa que 
más allá de cualquier diagnóstico epidemiológico que pueda ser realizado sobre el dengue y la problemática de salud que representa, es relevante notar que este tema también es instalado y percibido como un problema a nivel social. En el entramado social de discursos, el sentido de mayor pregnancia es el que postula que el dengue es un problema de todos y está por todos lados. Es la omnipresencia del mosquito y el poder de daño del virus lo que convierte al dengue en una amenaza real y un riesgo latente. De modo que, al problematizar el dengue, tanto como los diagnósticos epidemiológicos, revisten importancia los diagnósticos comunicacionales y sociales. (Rodríguez Zoya, 2018, p. 82)

A tal fin adquiere relevancia atender al tratamiento y la construcción de estas problemáticas sanitarias y sociales a través de la prensa y los medios de comunicación en general, en tanto estos constituyen un ámbito preponderante de circulación de los discursos sociales. En esta dirección, Rodríguez Zoya (2018) desarrolló un estudio sobre la circulación mediática del discurso social del dengue a través del cual afirma que esta problemática se configura como un objeto de gobierno complejo.

Así, el análisis del discurso periodístico pone de relieve la configuración de diversas estrategias en las que intervienen distintos actores sociales, por las cuales el dengue busca ser controlado. Rodríguez Zoya señala que "en virtud de esta clave interpretativa es posible reconocer el desarrollo de cuatro grandes tecnologías de control y gobierno del dengue, orientadas a distintos niveles de acción" (p. 84):

- El sanitario-comunicacional, a través de planes, programas y campañas de salud pública.

- El medioambiental, donde se destacan acciones de intervención sobre el espacio público fundamentalmente mediante fumigaciones para controlar al vector.

- El biotecnológico, donde se destacan las investigaciones y experimentación científica orientada a la modificación genética de los mosquitos para combatir la propagación del virus. 
- El de la sociedad civil, que comprende campañas y distintas acciones de educación y comunicación a través de las cuales se convoca a los individuos a modificar sus propias prácticas para que ellos intervengan en su espacio privado a fin de controlar al dengue, como por ejemplo mantener limpio el hogar y vaciar recipientes de agua para evitar la formación de larvas. En este plano se pone de manifiesto con mayor claridad el rol que juega la comunicación ante problemáticas complejas que son, a la vez, sociales y de salud. (Rodríguez Zoya, 2018, pp. 84-87)

\subsection{Ciclos "mediático-epidémicos": el encuentro de las lógicas periodís- tica, científica, epidemiológica y política}

Un caso especial y de interés para este artículo es el de los denominados ciclos "mediáticos-epidémicos", decididos por los medios para sus agendas y redes sociales, ejemplificados por Waisbord (2011), a partir de la extendida cobertura del dengue y de la gripe A (H1N1) en la Argentina (2009). De acuerdo con Shih et al. (2008), esos ciclos se definen como "dinámica": ausencia o presencia limitada en secciones especiales, duración prolongada y priorización del ciclo noticioso y vuelta a la cobertura mínima.

Si bien las noticias sobre salud han aumentado, especialmente en el caso de las epidemias, persisten problemas respecto del lenguaje, del contenido alarmista, entre otros aspectos. Esa apreciación no es ajena al periodismo que cubre noticias de salud y es contextualizada en el marco de las lógicas de la producción noticiosa. En este sentido, coincidimos con Waisbord (2011) en que

sería incorrecto criticar al periodismo por alimentar tales sensaciones sin evidencia ... Si los expertos anuncian la posibilidad de una crisis mundial y recomiendan subir el estado de alerta, la prensa actúa como espejo de sus convicciones ... A este consenso, se agrega la dificultad periodística de hablar en medias tintas. La duda científica es contraria a la certeza periodística. Incógnitas sobre la letalidad y proceso de expansión de la gripe $\mathrm{A}$, que son comunes entre los expertos, no encajan ni en el titular convencido y tajante ni en la búsqueda de la afirmación sucinta. (pp. 189-190) 


\section{Modelo para armar: una propuesta de investigación y comunicación}

A continuación, se presentan cinco puntos básicos a considerar en la comunicación de las políticas públicas en general y de las epidemias en particular. No se trata de un modelo acabado, ni mucho menos exhaustivo. Es una propuesta para propiciar el diálogo permanente con los hallazgos de las investigaciones y sus marcos teóricos, fortalecer institucionalmente la capacidad de los programas, planes y la formación de los decisores, así como para comprender la comunicación en tanto conocimiento y práctica.

\subsection{Investigación en la formulación y comunicación de políticas públicas de salud}

Sostenemos que la investigación es relevante para la toma de decisiones, ya sea que se trate de estudios cualitativos, cuantitativos, estudios bibliográficos, análisis discursivos, documentales, o más recientemente, investigación en implementación, entre otros, o que se trate de investigaciones realizadas por la misma gestión pública o por universidades o centros de investigación.

Cabe señalar que cuando nos referimos a la investigación estamos pensando en la evidencia que aportan los hallazgos, pero también en la construcción del problema de investigación. Más allá de las diferentes maneras y enfoques de encarar teórica y metodológicamente, y de gestionar la investigación, la relevancia se asienta en la continuidad de la práctica investigativa para formular, implementar y comunicar políticas. No se trata de pasos metodológicos ni de fases o momentos específicos de las políticas, más bien se trata de un proceso continuo en el cual la consideración de hallazgos de investigaciones es la base a partir de la cual se realimentan nuevas decisiones.

Por ejemplo, ante una epidemia, tomar en cuenta la bibliografía producida en el país y en el exterior sobre los resultados obtenidos por las campañas de prevención implementadas respecto de los objetivos comunicacionales o bien evaluar los contenidos de mensajes considerando las opiniones de los públicos, pueden convertirse en antecedentes o insumos para el diseño de nuevas piezas comunicacionales u otro tipo de intervenciones en el espacio público (Petracci \& Rodríguez Zoya, 2018a). 


\subsection{Fortalecimiento institucional de la comunicación en agencias guber- namentales}

La aceptación de la dimensión comunicacional de las políticas públicas de salud por los decisores, así como la creación y el fortalecimiento de áreas de gobierno que incluyan a la comunicación en un sentido amplio (más allá del tradicional rol de las oficinas de prensa) ha crecido paulatinamente de la mano de procesos políticos y del lugar central de las nuevas tecnologías de información y comunicación. A nuestro entender, el fortalecimiento institucional refiere tanto a la generación de áreas o programas destinados a pensar y gestionar los aspectos comunicacionales como a la formación de decisores en materia comunicacional.

En la Argentina, un caso que ha ejemplificado el fortalecimiento institucional de la comunicación, que vincula tomas de decisión en comunicación, gestión pública y epidemias es el de la Coordinación General de Información Pública y Comunicación (CGIPyC) del Ministerio de Salud de la Nación Argentina. Su creación en 2009 coincidió con la epidemia de Gripe A (H1N1), declarada pandemia por la Organización Mundial de la Salud (OMS) en junio de ese mismo año.

En relación con este caso, Petracci \& Rodríguez Zoya (2018b) plantean que

ante ese hecho sanitario, si bien las acciones de la CGIPyC estuvieron centradas en la producción de contenidos en soportes gráficos, radiales y audiovisuales, [las acciones comunicacionales] no fueron meramente el resultado del diseño técnico de un grupo de expertos sino, sobre todo, el logro de un reconocimiento institucional del área por la participación en el "comité de crisis", responsable del monitoreo de la evolución de la pandemia y de las respuestas sanitarias. (p. 125)

Para Bruno et al. (citados en Petracci \& Rodriguez Zoya, 2018b), algunos logros resultantes de la participación de la CGIPyC en el "comité de crisis" fueron los siguientes: "la atención sostenida de la demanda informativa de los medios masivos, la decisión de evitar la difusión diaria de cifras de personas fallecidas y la conformación de nuevos partes informativos" (pp. 125-126). 
Dicho en otros términos: "la CGIPyC dio un paso no sólo en la formulación sino también en la implementación de estrategias de comunicación desde un lugar institucional nuevo" (pp. 125), lo que fortaleció a la dimensión comunicacional como dimensión constitutiva de la política pública y desde una búsqueda de transformación del modo de concebir el alcance de lo comunicacional bajo el supuesto de la necesidad de considerar, además de los mensajes informativos y preventivos, a la dinámica y el estado de los servicios de salud y las políticas sanitarias.

La CGIPyC afirma en uno de sus documentos que

un escollo fundamental para este reposicionamiento estratégico es que la comunicación ha sido tradicionalmente concebida (incluso por algunos de nuestros colegas comunicadores) estrictamente como el manejo de los medios y el cuidado de la imagen pública de la autoridad sanitaria. Por supuesto que también es habitual que los y las comunicadores seamos reconocidos por ese don, arte $u$ oficio para "traducir" el saber biomédico en mensajes "culturalmente adecuados" que colaboren en la prevención de enfermedades, la promoción de hábitos saludables o el compromiso de la población con el logro de metas previamente establecidas por los decisores de la política sanitaria. Pero difícilmente se dimensiona la potencia de la comunicación para transformar la cultura organizacional, crear y recrear otros sentidos posibles y mejorar las interacciones con interlocutores, públicos de interés y ciudadanos. (Ministerio de Salud de la Nación Argentina [MSAL], 2011, p. 3)

Con relación al fortalecimiento de la formación de quienes toman decisiones en el ámbito público en el caso de las epidemias, el conocimiento y puesta en práctica, por ejemplo, de las recomendaciones de la Organización Mundial de la Salud (OMS, 2008) cobra importancia porque de estas se desprende otro desafío a los tomadores de decisión de la gestión pública: el abordaje y las estrategias comunicacionales basadas en investigaciones. A continuación, exponemos una síntesis comentada de esas recomendaciones enfatizando las derivaciones comunicacionales e investigativas: 
- Confianza: una comunicación con la población que genere o refuerce ese sentimiento entre decisores y ciudadanía para anunciar riesgos y prácticas preventivas.

- Anuncios tempranos: una comunicación temprana de un riesgo real o eventual para la salud es una señal de alerta para minimizar la amenaza que supone una enfermedad infecciosa, evitar rumores e información errónea y, por otro lado, para contribuir a reforzar la confianza de la ciudadanía en las autoridades sanitarias.

- Transparencia: una comunicación que proporcione información clara y completa sobre el riesgo real o eventual que un brote representa y su control refuerza la confianza y, más aún, si se trata de un anuncio temprano.

- Escuchar al público: una comunicación conocedora de su público será conocedora de la percepción de riesgos y la representación de las medidas de prevención en base a cómo la recepción percibe riesgos y se representa las medidas de prevención en base al trasfondo cultural de la recepción.

- Planificación: de actividades y contenidos. (OMS, 2008, p. 5)

Desde nuestro abordaje de la comunicación gubernamental de las epidemias a través del campo de la "Comunicación y Salud", coincidimos con las recomendaciones de la OMS. Sin embargo, nos interesa destacar una idea expuesta en las secciones anteriores para que esas recomendaciones puedan integrarse en la práctica concreta de toma de decisiones en escenarios complejos como los de las epidemias. La aplicación de dichas recomendaciones será tanto mejor en la medida que esté integrada a la planificación, la investigación y, especialmente, la investigación evaluativa y a la investigación en implementación, en el proceso de las políticas públicas. Un anuncio "temprano" y "transparente" podrá hacerse si la política comunicacional de la salud haya sido también formulada temprana y previamente, siendo parte de una práctica de toma de decisiones, basada en los hallazgos de investigaciones.

\subsection{Comprensión disciplinar de la comunicación de epidemias}

Pensar la comunicación pública de epidemias desde el campo de "Comunicación y Salud" implica asumir una perspectiva que reconoce y problematiza la especificidad y la complejidad disciplinar de este campo, así como de la heterogeneidad de temas y problemas que el mismo comprende. En esta clave, la comunicación y la salud no constituyen disciplinas independientes y 
subsidiarias la una de la otra, sino que por el contrario se entrelazan, dialogan y articulan mutuamente.

Asumir esta posición supone correrse de la concepción instrumental de la comunicación como herramienta o recurso en pos de las problemáticas de salud, y así también evitar que el diseño y la implementación de una estrategia comunicacional sean considerados un servicio al cual acudir a posteriori de la irrupción de una epidemia. En línea con esta posición, Kaufman (2011) reflexiona sobre las "difíciles" relaciones entre epidemiología y comunicación:

Una dificultad conceptualmente estructural ... reside en la premisa de que la primera registraría eventos susceptibles de determinación objetiva e independiente de los comportamientos sociales, en tanto que el campo de la comunicación remitiría a un plexo de representaciones de aquellos acontecimientos objetivos y verificables. Al entender el campo de la comunicación como una representación subordinada a los acontecimientos epidemiológicos, se le confiere una finalidad de enunciación de dichos acontecimientos, y se diseñan de manera racional mensajes cuyo destino asignado consiste en modificar comportamientos, hábitos y percepciones, sobre la base del cuerpo de conocimientos científicos tal como se dispone de ellos. De esta manera, el campo de la comunicación tendría una finalidad subordinada a la epidemiología, consistente en ofrecerle un servicio de mediación entre el conocimiento científico y su intelección pública. La divulgación científica desempeña en este terreno un papel importante, y la persuasión dirigida a modificar comportamientos, más allá de una racionalidad comunicativa, desempeña a su vez un papel. Integra estas premisas, corrientemente asumidas, el supuesto de que los medios de comunicación desempeñan un papel intersticial entre instituciones y audiencias, entre producción del conocimiento y su difusión pública, entre educadores y públicos amplios extracurriculares. (pp. 145-146)

La comprensión de la comunicación pública de epidemias como tema de "Comunicación y Salud" nos lleva a interrogar las relaciones entre comunicación y epidemiología, tomándose distancia de las representaciones y las premisas que sustentan la idea que cada una de estas constituyen campos disciplinares autónomos, con ámbitos de acción y modos de proceder propios, que entrarían en relación (esporádica y repentinamente) ante la urgencia comunica- 
cional que conlleva un brote epidémico. Tal como lo mencionamos precedentemente, considerar la comunicación de las políticas públicas de salud (en general) y de las epidemias (en particular) nos coloca en una interfaz que articula indisolublemente la comunicación y la salud.

La puesta en relación entre la comunicación y la salud ... no consiste en un acople, fusión o solapamiento de los dos dominios. Tampoco cabría pensar tal vinculación en términos de una primacía de uno sobre el otro. Por el contrario, el campo de Comunicación y Salud constituye una emergencia en tanto se configura como un espacio de propiedades cualitativamente nuevas, es decir, que implica nuevas relaciones y modos de organización de la comunicación y la salud. (Rodríguez Zoya, 2017, p. 45)

En este sentido, la comunicación y la salud se coproducen, se implican y conforman conjuntamente a la "Comunicación y Salud" como un campo emergente con lógica propia. El desafío de pensar la especificidad disciplinar de la comunicación de epidemias radica en atender las múltiples racionalidades, saberes y puntos de vista de los diversos actores involucrados en la cuestión como por ejemplo: funcionarios gubernamentales y tomadores de decisión; profesionales y agentes de la salud; científicos, investigadores y especialistas en el tema de la epidemia; medios de comunicación, periodistas y comunicadores; y más ampliamente la ciudadanía o población considerada en el escenario epidémico.

Particularmente, uno de los aspectos a indagar concierne a los conocimientos y a las representaciones que estos actores sociales tienen tanto de la comunicación como de los temas o problemas de salud a los que las epidemias refieren. Por eso, resulta fundamental el desarrollo de la investigación como práctica continua y transversal al proceso de formulación, implementación y comunicación de políticas públicas de salud.

\subsection{Riesgo y noticiabilidad en la comunicación de epidemias}

La problematización de la comunicación de epidemias y de las medidas preventivas a adoptar ante un brote epidémico nos conduce a poner en consideración la noción de riesgo, asociada de manera inseparable a la de probabilidad 
e incertidumbre. Se trata de comprender las mediaciones entre la producción de un conocimiento experto sobre las características de un brote epidémico y su traslado a quienes, en base a ese conocimiento, tendrán a cargo la construcción de las noticias o bien la producción de piezas comunicacionales. En otros términos: la incertidumbre asociada a los riesgos externos es un desafío para la comunicación de epidemias teniendo en cuenta las características globales de la comunicación de este tiempo. Giddens (1999) señala que la noción de riesgo

parece haber tomado cuerpo en los siglos XVI y XVII, y fue acuñada por primera vez por exploradores occidentales cuando realizaban sus viajes por el mundo ... El riesgo es la dinámica movilizadora de una sociedad volcada en el cambio que quiere determinar su propio futuro en lugar de dejarlo a la religión, la tradición o los caprichos de la naturaleza ... La idea de riesgo siempre ha estado relacionada con la modernidad; pero quiero defender que en el período actual este concepto asume una nueva y peculiar importancia. Se suponía que el riesgo era una forma de regular el futuro, de normalizarlo y traerlo bajo nuestro dominio. Las cosas no han resultado así. Nuestros mismos intentos por controlar el futuro tienden a volver hacia nosotros, forzándonos a buscar formas diferentes de ligarlo a la incertidumbre. (pp. 34-36)

El riesgo y la incertidumbre constituyen factores centrales en relación con las epidemias y, por lo tanto, resultan categorías clave a la hora de pensar su comunicación. A este respecto se plantean dos escenarios comunicacionales posibles. Por un lado, si los responsables del saber científico y experto, los organismos internacionales y los gobiernos consideran que la probabilidad de riesgo ante una epidemia es alta, la comunicación se caracterizará por un alto perfil mediático, oscilante entre el énfasis y la espectacularidad. Si el riesgo resultó menor al esperado, la comunicación será señalada como alarmista, tal como apuntan las investigaciones presentadas sobre la comunicación de la gripe A (H1N1) en la Argentina en 2009.

Por otro lado, contrariamente, si los responsables del saber científico y experto, los organismos internacionales y los gobiernos consideran que la probabilidad de riesgo ante una epidemia es baja, la comunicación se caracterizará por un bajo perfil mediático. Si el riesgo resultara mayor al esperado, la 
comunicación será criticada por descuido o bien por complicidades, como señala Giddens (1999) respecto del caso de la carne de vaca contaminada en Inglaterra. Para dicho autor, "no sabemos, sencillamente, cuál es el nivel de riesgo, y en muchos casos no lo sabremos hasta que sea demasiado tarde" (p. 41).

\subsection{Actualización y renovación de abordajes}

El pasaje de la comprensión disciplinar señalada precedentemente a la aplicación tanto de tradicionales como de nuevos "abordajes" (Gambaccini, 2018) requiere el reconocimiento definitivo de las limitaciones del paradigma informacional y de una concepción de la comunicación en el campo de la salud, cuyo foco esté puesto exclusivamente en los cambios de comportamiento a partir de una construcción del problema basada en motivaciones individuales.

Esto último no significa que los cambios individuales en los comportamientos sean abandonados y no sean necesarios como objetivo comunicacional de una política pública en salud, sino que el enfoque desde el cual esos objetivos son planteados, especialmente en el caso de las epidemias, ancle en la comprensión de escenarios de riesgo e incertidumbre, y de cambio en las modalidades de participación social, en el marco de la trama comunicacional actual. Waisbord (2015) explica que

en sintonía con innovaciones teóricas y analíticas en las ciencias sociales, la comunicación contemporánea señala la necesidad de entender dimensiones políticas como desigualdades de poder, activismo y acciones estratégicas, recursos sociales e identidades culturales. (pp. 142-143)

En el plano de la práctica, los "abordajes" (Gambaccini, 2018) comprenden diferentes tipos de estrategias comunicacionales en los niveles comunitario (educación por pares y acercamientos basados en el diálogo) y mediático (campañas de prevención) u otras más recientes, como las aplicaciones destinadas a la salud (eHealth) o actividades participativas online o en redes sociales (crowdsourcing y slacktivism). 


\section{Discusión}

En esta instancia del artículo, nos interesa formular una serie de apreciaciones y reflexiones sobre el trabajo realizado en dos planos. Por un lado, con respecto del corpus de investigaciones sociales sobre epidemias sistematizadas y analizadas. Por el otro, en relación con el tema general de la comunicación pública de epidemias y las consideraciones y desafíos que plantea su abordaje desde la perspectiva de la "Comunicación y Salud".

Con respecto del corpus de investigaciones seleccionadas y analizadas, consideramos la necesidad de ampliación del mismo con investigaciones cuyo objetivo sea la medición del impacto de las campañas de prevención. Si bien es cierto que ese tipo de medición requiere diseños complejos y costosos de implementar (dado el efecto sinérgico de los medios de comunicación y, más aún, de las redes sociales), resulta imprescindible el conocimiento sobre los resultados obtenidos respecto de lo que se planificó comunicar.

Respecto del análisis y la propuesta de este artículo, cabe señalar que la misma afronta dos temporalidades en tensión: la urgencia de las epidemias y el trabajo a más largo plazo implicado en los aspectos del denominado "modelo para armar" de investigación y comunicación de políticas públicas de salud. El desafío de abordar la comunicación de epidemias y las políticas públicas, relativas a esta cuestión, conlleva congeniar ese desfasaje entre la urgencia que imprimen las epidemias y los tiempos de mediana y larga duración que implica tanto el trabajo en investigación y comunicación como el proceso de las políticas públicas. En otros términos, que los tiempos de las epidemias y los tiempos de la comunicación sean sintetizados en el momento oportuno.

La comunicación pública de epidemias también nos conduce a pensar otra tensión entre comunicación y epidemias. Se trata de una "tensión constitutiva" entre la comunicación que es y requiere ser situada, contextual y orientada a un público definido, por un lado; $y$, por el otro, las epidemias que, por definición, son fenómenos que ocurren a nivel poblacional, masivo, que desconocen fronteras territoriales y culturales o públicos específicos. 


\section{Conclusiones}

Destacamos la pertinencia del campo de la "Comunicación y Salud" para pensar y aportar a la comunicación pública de las epidemias. A partir de una cartografía heterogénea, las aperturas epistemológicas de la incorporación del pensamiento complejo y las interrelaciones teórico-prácticas del campo, hemos presentado el análisis de investigaciones que profundizan en la discursividad y en los escenarios político-sociales de diferentes epidemias ocurridas en la Argentina, y formulado los lineamientos de un marco de investigación y comunicación.

Hemos concebido a ese marco de investigación como un "modelo para armar" (apartado 5), no porque sea un modelo cerrado ni un conjunto de pasos de un diseño metodológico, sino justamente para destacar su contrapartida y lo que resta por hacer. Entendemos que ese marco para la comunicación de las epidemias parte del conocimiento producido por la investigación, teórica y empírica, como componente constitutivo de las políticas públicas. Cobran especial relevancia aquellas investigaciones sociales cuyos hallazgos ofrecen una construcción de conocimiento sobre el modo en que las epidemias fueron comunicadas y las relaciones entre el contenido comunicacional de la prevención y lo que esa comunicación visibilizó acerca de trasfondos y dispositivos gubernamentales propios de cada epidemia.

En esa dirección, los resultados presentados conforman un puntapié inicial para desarrollar el primer punto de la propuesta (investigación en la formulación y comunicación de políticas públicas de salud) a partir de estudios cuya construcción de la comunicación de epidemias en tanto problema se asienta en el subapartado 5.3 ("Comprensión disciplinar de la comunicación de epidemias").

Los tomadores de decisión en la gestión pública epidemiológica y comunicacional en salud son actores clave en el escenario que venimos desarrollando y destinatarios principales de la propuesta, especialmente en lo que respecta al subapartado 5.5 (“Actualización y renovación de abordajes") y al subapartado 5.4 ("Riesgo y noticiabilidad en la comunicación de epidemias"). Por otro lado, la propuesta incluye y pone de relieve un aspecto desatendido durante años en los ministerios de salud: la necesidad de fortalecimiento del sector salud en la estructura institucional desde una perspectiva que, como venimos 
sosteniendo en este trabajo, priorice la dimensión comunicacional de las políticas públicas en salud y, en el caso de las epidemias, conjugue las nociones de información pública, riesgo y noticiabilidad.

\section{Fuentes consultadas}

Adhanom Ghebreyesus, T. (2018, Febrero 12). ¿Podemos conseguir un mundo sin pandemias? Organización Mundial de la Salud. http://www9.who.int/dg/speeches/2018/pandemic-free-world/es/

Araújo, I., \& Cardoso, J. (2007). Comunicação e Saúde. Fiocruz.

Cardoso, J., \& Araujo, I. (2009). “Comunicação e Saúde”. En I. Pereira \& J. Lima (Eds.), Dicionário da Educação Profissional em Saúde. Fiocruz.

Cófreces, P., Ofman, S., \& Stefani, D. (2014). "La comunicación en la relación médico-paciente. Análisis de la literatura científica entre 1990 y 2010”. Revista de Comunicación y Salud, 4, 19-34.

Cuberli, M., \& Soares de Araújo, I. (2015). Las prácticas de la comunicación y salud: intersecciones e intersticios. En M. Petracci (Coord.), La salud en la trama comunicacional contemporánea. Prometeo.

Del Pozo, J., Román, A., Alcántara, R., \& Domínguez, M. (Coords.) (2015). Medios de comunicación y salud. Astigi.

Eynard, M., \& Drovetta, R. (2011). El vector subversivo: la epidemia de dengue en abril de 2009 en la ciudad de Córdoba. En M. Petracci \& S. Waisbord (Comps.), Comunicación y Salud en la Argentina (pp. 89116). La Crujía Ediciones.

Gambaccini, A. (2018). Abordajes comunicacionales de las políticas de salud. En M. Petracci, \& P. Rodríguez, Comunicación y Salud: la investigación en el proceso de las políticas públicas (pp. 32-41). Teseo. 
Giddens, A. (1999). Un mundo desbocado. Los efectos de la globalización en nuestras vidas. Taurus.

Jait, A. (2011). Los 100 días que vivimos en peligro: la construcción del nuevo virus de la influenza a $(\mathrm{H} 1 \mathrm{~N} 1)$ en Clarín. En M. Petracci \& S. Waisbord (Comps.), Comunicación y Salud en la Argentina (pp. 117-142). La Crujía Ediciones.

Kaufman, A. (2011). Hacia una epidemiología del pánico mediático. En M. Petracci \& S. Waisbord (Comps.), Comunicación y Salud en la Argentina (pp. 143-152). La Crujía Ediciones.

Loewy, M., \& Petracci, M. (2015). Salud y noticiabilidad. Las perspectivas de periodistas de medios gráficos de Argentina. En M. Petracci (Coords.), La salud en la trama comunicacional contemporánea (pp. 113-140). Prometeo Libros.

Ministerio de Salud de la Nación Argentina, MSAL. (2011). Funciones Básicas de Información y Comunicación en Salud Pública. Coordinación de Información Pública y Comunicación, MSAL.

Morin, E. (1995). Epistemología de la complejidad. En D. Fried Schnitman (Comp.), Nuevos paradigmas, cultura y subjetividad. Paidós.

Morin, E. (2001). Introducción al pensamiento complejo. Gedisa.

Organización Mundial de la Salud, OMS. (2008). Guía de la Organización Mundial de la Salud para planificar la comunicación en caso de brotes epidémicos. OMS. https://apps.who.int/iris/bitstream/ handle/10665/44162/9789243597447_spa.pdf;jsessionid=FEEC8478346B7A7AD32FAD6B0C2D28BB? sequence $=1$

Petracci, M., Quevedo, L., \& Vacchieri, A. (1998). Los modelos político comunicativos del SIDA y el cólera en la Argentina, 1991-1993. ZER Revista de Estudios de Comunicación, Universidad del País Vasco, 4, 199- 218. 
Petracci, M. (2012). Comunicación y Salud: un campo diverso y pujante. Organicom, Revista Brasileira de Comunicação Organizacional e Relações Publicas. Edição Especial, 9(16/17), 40-49.

Petracci, M. (2015a). Ámbitos público y mediático en Comunicación y Salud. Correspondencias \& Análisis, 5, 268-288. https://doi.org/10.24265/ cian.2015.n5.15

Petracci, M. (Coord.) (2015b). La salud en la trama comunicacional contemporánea. Prometeo.

Petracci, M., \& Rodríguez Zoya, P. (2018a). Claves de lectura en Comunicación y Salud. En M. Petracci \& P. Rodríguez, Comunicación y salud: la investigación en el proceso de las políticas públicas (pp. 11-19). Teseo.

Petracci, M., \& Rodríguez Zoya, P. (2018b). Perspectivas comunicacionales de tomadores de decisión en salud pública. Argentina, 2011-2014. En M. Petracci \& P. Rodríguez Zoya (2018). Comunicación y Salud: la investigación en el proceso de las políticas públicas (pp. 121-134). Teseo.

Petracci, M., \& Rodríguez Zoya, P. (2018c). Relaciones entre políticas públicas de salud, epidemias y periodismo. Una lectura a través de la investigación social y comunicacional en la Argentina. En curso "Epidemias, Jornalismo e Políticas Públicas de Saúde". Instituto de Comunicación e Información Científica y Tecnológica en Salud y la Fundación Oswaldo Cruz FIOCRUZ, Rio de Janeiro, Brasil.

Petracci, M., \& Rodríguez Zoya, P. (2019). Los tomadores de decisión como actores clave en la investigación sobre comunicación de políticas públicas de salud. En D. Catalán, C. Peñafiel \& J. Terrón (Coords.), ¿Por qué la comunicación en salud es importante? Avances e investigación (pp. 193-205). Aranzadi; Thomson Reuters.

Petracci, M., Sánchez, V., Schwarz, P., \& Mendes, A. (2017). La relación médico-paciente en la indagación académica contemporánea. En M. Petracci, P. Schwarz \& P. Rodríguez Zoya (2017). Comunicación y Salud. Las relaciones entre médicos y pacientes en la Modernidad Tardía (pp.105-181). Teseo. 
Petracci, M., \& Waisbord, S. (2011). Introducción. En M. Petracci, \& S. Waisbord (2011). Comunicación y Salud en la Argentina (pp. 9-23). La Crujía.

Polino, C., Chiappe, L., \& Fazio, M. (2006). Análisis de la oferta informativa sobre ciencia y tecnología en los principales diarios argentinos. Informe final. Buenos Aires: Observatorio de Ciencia, Tecnología e Innovación Productiva, Secretaría de Ciencia, Tecnología e Innovación Productiva.

Ranger, T., \& Slack, P. (Comps.) (1992). Epidemics and Ideas. Essays on the Historical Perception of Pestilence. Cambridge University Press.

Rodríguez Zoya, P. (2017). Notas para pensar la complejidad del campo de Comunicación y Salud. En M. Petracci, P. Schwarz \& P. Rodríguez Zoya (2017). Comunicación y Salud. Las relaciones entre médicos y pacientes en la Modernidad Tardia (pp. 13-68). Teseo.

Rodríguez Zoya, P. (2018). Problemas complejos de Comunicación y Salud: reflexiones en torno al gobierno del dengue. En M. Petracci \& P. Rodríguez Zoya, Comunicación y Salud: la investigación en el proceso de las políticas públicas (pp. 77-90). Teseo.

Rodríguez Zoya, P. (2019). Comunicación y Salud: un campo transdisciplinar, complejo y emergente. En D. Catalán, C. Peñafiel \& J. Terrón, ¿Por qué la comunicación en salud es importante? Avances e investigación (pp. 89-103). Aranzadi; Thomson Reuters.

Rosenberg, C. (1992). Explaining epidemics and other studies in the history of medicine. Cambridge University Press.

Shih, Tsung-Jen, Wijaya, R., \& Brossard, D. (2008). Media Coverage of Public Health Epidemics: Linking Framing and Issue Attention Cycle Towards an Integrated Theory of Print News Coverage of Epidemics. Mass Communication \& Society, 11(2), 141-160.

Tabakman, R. (2011). La salud en los medios. Medicina para periodistas... periodismo para médicos. Internet Medical Publishing. 
Waisbord, S. (2011). Cuando la salud es titular: dengue, Gripe A y ciclos "mediático epidémicos". En M. Petracci \& S. Waisbord (Comps.), Comunicación y Salud en la Argentina (pp. 185-197). La Crujía Ediciones.

Waisbord, S. (2015). Perspectivas críticas en Comunicación y Salud: ideas para investigaciones futuras. En M. Petracci (Coord.), La salud en la trama comunicacional contemporánea (pp. 141-151). Prometeo. 